OPEN ACCESS

Edited by:

András Bikov,

The University of Manchester,

United Kingdom

Reviewed by:

Stefan Mihaicuta,

Victor Babes University of Medicine

and Pharmacy, Romania

Silvano Dragonieri,

University of Bari Aldo Moro, Italy

${ }^{*}$ Correspondence:

Shijie Xin

sjxin@cmu.edu.cn

Specialty section:

This article was submitted to

Cardiovascular Epidemiology and

Prevention,

a section of the journal

Frontiers in Cardiovascular Medicine

Received: 03 August 2021

Accepted: 25 October 2021

Published: 18 November 2021

Citation:

Zhang J, Zhang Z, Fu L, Wang L,

Yang $Y$, Wang $H$, Zhou $B$, Wang $W$, Zhang $J$ and Xin S (2021) Obstructive

Sleep Apnoea in Stanford Type B

Aortic Dissection Is Associated With

Multiple Imaging Signs Related to Late Aortic Events.

Front. Cardiovasc. Med. 8:752763.

doi: 10.3389/fcvm.2021.752763

\section{Obstructive Sleep Apnoea in Stanford Type B Aortic Dissection Is Associated With Multiple Imaging Signs Related to Late Aortic Events}

\author{
Jiawei Zhang ${ }^{1}$, Zhe Zhang ${ }^{1}$, Lingyu Fu ${ }^{2}$, Lei Wang ${ }^{1}$, Yu Yang ${ }^{1}$, Hao Wang ${ }^{3}$, Baosen Zhou ${ }^{2}$, \\ Wei Wang ${ }^{4}$, Jian Zhang ${ }^{1}$ and Shijie Xin ${ }^{1 *}$ \\ ${ }^{1}$ Department of Vascular Surgery, The First Hospital of China Medical University, Shenyang, China, ${ }^{2}$ Department of Clinical \\ Epidemiology and Evidence Medicine, The First Hospital of China Medical University, Shenyang, China, ${ }^{3}$ Department of \\ Vascular Surgery, Beijing Friendship Hospital, Capital Medical University, Beijing, China, ${ }^{4}$ Department of Respiratory \\ Medicine, The First Hospital of China Medical University, Shenyang, China
}

Background: Obstructive sleep apnoea (OSA) is highly prevalent in patients with Stanford type B aortic dissection (TBAD). Few studies have evaluated the effects of OSA on vascular changes in TBAD patients. This study aimed to explore the effect of OSA on aortic morphological changes in TBAD patients and its relation to late aortic events (LAEs).

Methods: This case-control study included 143 TBAD patients. The diameters of different parts of the aorta were measured based on computed tomography angiography (CTA). According to the apnoea-hypopnoea index (AHI), OSA was classified as mild $(5 \leq A H I \leq 15)$, moderate $(15<A H I \leq 30)$, or severe $(A H I>30)$. The false lumen (FL) status was evaluated and classified as partially thrombosed, patent, or completely thrombosed.

Results: The OSA prevalence in TBAD patients was $64.3 \%$, and image differences related to LAEs between TBAD patients with and without OSA included the maximum aortic diameter at onset ( $37.3 \pm 3.9$ vs. $40.3 \pm 4.5 \mathrm{~mm}, p<0.001)$, the FL diameter of the proximal descending thoracic aorta ( $16.0 \pm 6.8 \mathrm{vs}$. $20.3 \pm 4.7 \mathrm{~mm}, p<0.001)$, and the proportion of the FL that was partially thrombosed (39.2 vs. 64.1\%, $p=0.004$ ). Additionally, in the multivariable analysis of patients with OSA, the risks of an aortic diameter $\geq 40 \mathrm{~mm}$, a proximal descending aorta $\mathrm{FL} \geq 22 \mathrm{~mm}$ and a partially thrombosed FL were 4.611 (95\% Cl: 1.796-11.838, $p=0.001$ ), 2.544 (95\% Cl: 1.050-6.165, $p=0.039$ ), and 2.565 (95\% Cl: 1.167-5.637, $p=0.019)$, respectively, after adjustment for confounding factors. Trend tests showed that the risks of an aortic diameter $\geq 40 \mathrm{~mm}$ and a partially thrombosed FL increased with increasing OSA severity.

Conclusions: TBAD patients with moderate to severe OSA have aortic dilatation in different parts of the aorta. OSA is an independent risk factor for multiple imaging signs related to LAEs, suggesting that OSA is an important factor affecting the prognosis of TBAD patients.

Keywords: Stanford type B aortic dissection, obstructive sleep apnoea (OSA), late aortic events, aortic morphological changes, aortic dilatation 


\section{INTRODUCTION}

Stanford type B aortic dissection (TBAD) is a catastrophic vascular disease with high mortality and poor prognosis $(1,2)$ that is characterized by the blood passing through the first one-third of the external media in the aortic wall (3). The annual incidence of $\mathrm{AD}$ is estimated to be 2.6-3.6 per 100,000 adults worldwide (4-6). Most patients die within the first week, and $\sim 25-50 \%$ of patients who survive the acute phase require surgery during the chronic phase $(7,8)$. The overall inhospital mortality of TBAD was reported to be $13 \%$. Despite the increase in the use of thoracic endovascular aortic repair (TEVAR) and the application of hybrid surgery, in-hospital mortality has not changed significantly in the past 20 years (9). Compared with medical therapy, TEVAR has proven to be more effective in improving aortic remodeling and long-term survival (10). However, neither TEVAR nor medical therapy can fully prevent aortic wall degeneration or disease progression. Approximately $35 \%$ of patients treated with TEVAR and $65 \%$ of patients receiving medical therapy develop late aortic events (LAEs) within 5 years $(11,12)$.

The occurrence of LAEs severely affects the prognosis of patients with $\operatorname{TBAD}(13,14)$. In most studies, LAEs were defined as the development of aortic expansion $(>55 \mathrm{~mm})$, rapid dilatation of the dissected aorta ( $>10 \mathrm{~mm}$ per $10-12 \mathrm{mo}$ ), new dissection, malperfusion, rupture, or impending rupture and aortic-related death after patients were discharged following surgery or medical treatment $(10,15-19)$. Previous studies have demonstrated that several predictors could be used to identify TBAD patients at high risk for aortic expansion during followup and predict the individual risk of LAEs. Radiologic predictors included an initial maximum diameter of the aorta $\geq 40 \mathrm{~mm}$ $(10,15,16,20-23)$, a proximal descending thoracic aortic false lumen (FL) diameter $\geq 22 \mathrm{~mm}$ (24), a partially thrombosed FL (17, 25-28), a large entry tear $>10 \mathrm{~mm}$ (10), a fusiform index $\geq 0.64$ (29), and ulcer-like projections (30, 31). Clinical predictors included younger age ( $<60$ years) $(32,33)$, heart rate $\geq 60 / \mathrm{min}$ (34), and Marfan syndrome (35). Laboratory findings involved fibrinogen-fibrin degradation product levels $\geq 20 \mathrm{mg} / \mathrm{ml}$ at admission (36) and peak C-reactive protein levels $\geq 9.61 \mathrm{mg} / \mathrm{dl}$ (37). Identification of these predictors might benefit patients through early TEVAR or closer follow-up and contribute to the development of individualized treatment strategies $(14,19,38)$.

Obstructive sleep apnoea (OSA) is characterized by recurrent upper airway obstruction with interruption of airflow and persistence of inspiratory effort during sleep (39) and is one of the most common risk factors for cardiovascular diseases (40). The prevalence of OSA in TBAD is $66.2-81.7 \%(41-43)$, which is dramatically higher than the reported incidence of 9$38 \%$ in the general population $(44,45)$. The potential correlation between OSA and TBAD was first reported by Sampol et al. (46). An increasing number of studies have shown that OSA is an important cause of AD (42, 47-49).

However, few studies have evaluated the effects of OSA on vascular changes in TBAD patients. The aim of this study was to explore the effect of OSA on aortic morphological changes in TBAD patients and its relation to LAEs.

\section{MATERIALS AND METHODS}

\section{Study Population}

From August 1, 2019, to July 1, 2021, a total of 167 TBAD patients were admitted to the vascular surgery department of the First Hospital of China Medical University. All patients underwent computed tomography angiography (CTA) examinations and arterial blood gas analysis on admission. We routinely performed sleep monitoring on the patients. We asked the patients' medical history and queried their electronic medical records to determine whether the patients had undergone polysomnography (PSG) for the first time or had been previously treated with continuous positive airway pressure (CPAP) for OSA or other respiratory diseases. Smoking history was determined as a history of smoking (current or former) or no history of smoking. Figure 1 illustrates the exclusion criteria for this study, including (1) type A AD; (2) patients with Marfan syndrome; (3) patients with traumatic dissection; (4) patients who refused to undergo sleep monitoring; (5) poor-quality CTA data or a lack of imaging data before surgery; and (6) aortic dissection rupture, shock, unconsciousness or other life-threatening situations. A total of 143 TBAD patients were ultimately enrolled in our study.

\section{Imaging Data}

CTA images were produced by a SIEMENS SOMATOM Definition Flash CT (Siemens Healthcare, Erlangen, Germany). The thickness of the CTA imaging slice was $1 \mathrm{~mm}$. The aortic morphology was measured using image processing software (IMPAX Client, Agfa HealthCare N.V., Version 6.5.3.1509). The imaging data we measured included (1) the maximum aortic diameter at onset (the first CTA scan was performed during the acute event on initial imaging of the aorta); (2) the maximum diameter of the descending aorta; (3) the FL diameter of the proximal descending thoracic aorta (the FL at the upper descending thoracic aorta on initial CTA); (4) the diameter of the distal aortic arch (at the level of the left subclavian artery, including the retrograde dissection extending to the proximal aortic arch); (5) the diameter of the descending aorta (at the level of origin, the main pulmonary artery); (6) the maximum diameter of the FL; (7) the FL status (completely thrombosed, partially thrombosed, patent); (8) the fusiform index (defined as $A /(B+C)$, where $A=$ maximum diameter of the descending aorta, $\mathrm{B}=$ diameter of the distal aortic arch, $\mathrm{C}=$ diameter of the descending aorta at the level of origin, the main pulmonary artery) (29); and (9) the number of dissection process-involved zones according to the Society for Vascular Surgery/Society of Thoracic Surgeons (SVS/STS) classification system reporting standards for TBAD (50).

\section{Sleep Study}

A sleep study was performed with a portable sleep-respiration monitor [PSM, PSM100A; Sealand Technology (Chengdu) Co., Ltd]. Sleep monitoring was performed before surgery and after all the patients were transferred from the intensive care unit to the general ward. The initial symptoms of each patient were relieved, which did not affect sleep monitoring due to pain or dyspnoea. Neither sedatives nor alcohol was used within 


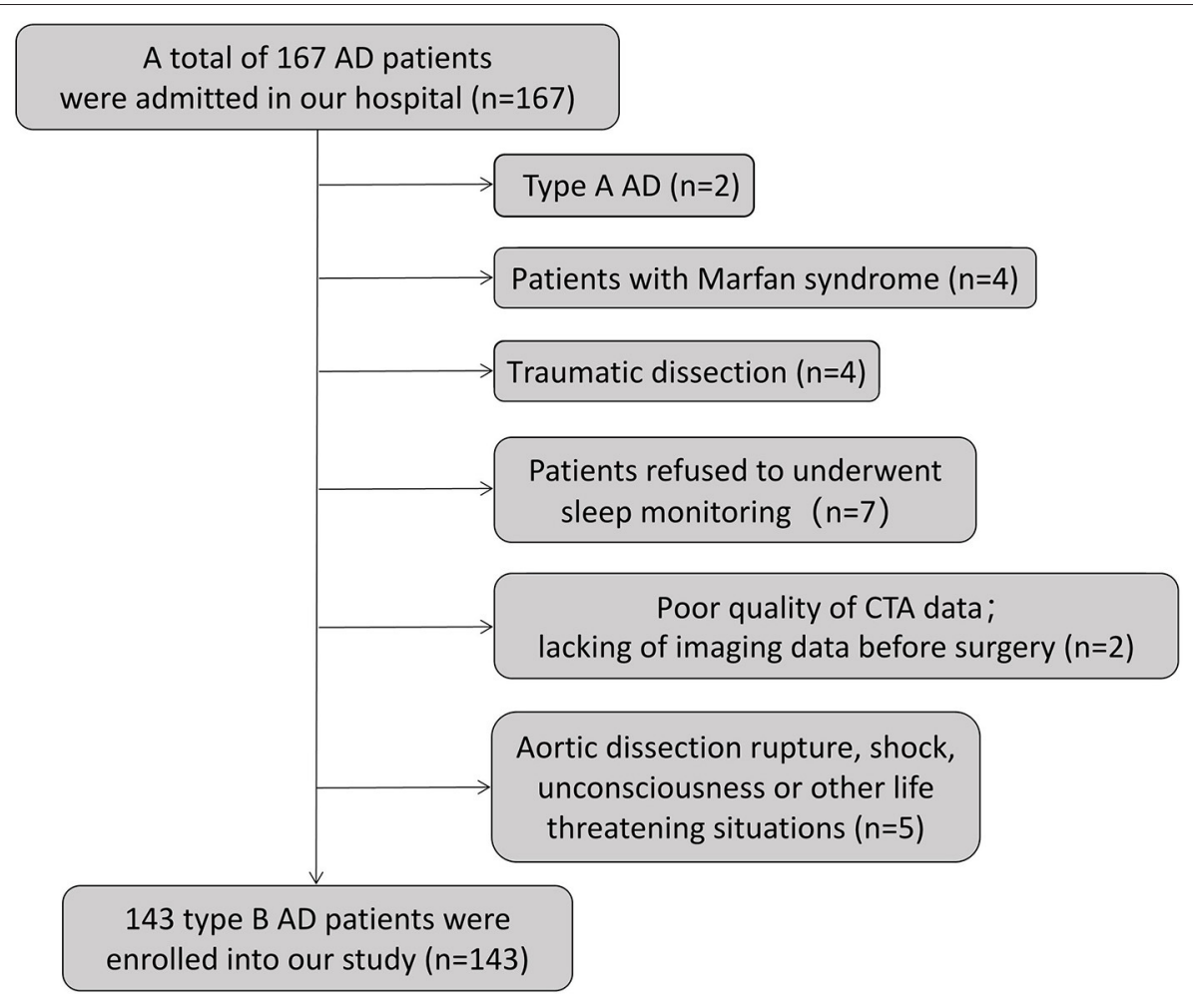

FIGURE 1 | Flow chart of the exclusion criteria.

$48 \mathrm{~h}$ before the study. The recording duration was between 10:00 P.M. to 7:00 A.M. and lasted at least $7 \mathrm{~h}$. The content of the records included the apnoea-hypopnoea index (AHI), nasal airflow pressure, chest movement, body position, snoring and fingertip oximetry. The diagnostic criteria for OSA refer to the American Academy of Sleep Medicine (AASM) Guidelines (2017) (51) and were defined as AHI $\geq 5$ events/h. OSA severity was categorized according to the AHI as follows: mild OSA (5 $\leq \mathrm{AHI} \leq 15)$, moderate OSA $(15<\mathrm{AHI} \leq 30)$, and severe OSA $(\mathrm{AHI}>30)$.

\section{Statistics}

All data are expressed as the mean \pm standard deviation (SD) or number of participants (percentages). Normality was assessed using the Shapiro-Wilk normality test. Student's $t$-test was used for comparisons between TBAD patients with or without OSA if the data fit the normal distribution, and the Mann-Whitney $U$ test otherwise. Pearson's chi-square test or Fisher's exact test was used to compare the percentages in different groups. Univariate and multivariate logistical regressions were performed to analyse the risk factors and risk magnitude for a maximum aortic diameter at onset $\geq 40 \mathrm{~mm}$, a diameter of the FL of the proximal descending thoracic aorta $\geq 22 \mathrm{~mm}$ and a partially thrombosed FL. Variables with a $p \leq 0.05$ on univariate analysis and clinically important factors [age, hypertension, and body mass index (BMI)] were included in the multivariate analysis. The results are expressed as odds ratios (ORs) and 95\% confidence intervals
(CIs). $P \leq 0.05$ were considered significant. Statistical analyses were performed using SPSS version 26 (IBM Corp.). The minimal sample size was estimated by PASS 11 (NCSS, Kaysville, Utah) and met the requirements of our study (for a maximum aortic diameter at onset $\geq 40 \mathrm{~mm}$, a FL diameter of the proximal descending aorta $\geq 22 \mathrm{~mm}$, and a partially thrombosed FL, the minimum sample size of TBAD patients with and without OSA was 58 and 32, 74 and 41, 87 and 48, respectively).

\section{RESULTS}

\section{Baseline Characteristics and Prevalence of OSA Among TBAD Patients}

Of all 143 patients, the mean age was $52.0 \pm 11.7$ (years), and the average AHI was $15.1 \pm 15.5$ (times/h). Most of the patients underwent sleep monitoring for the first time, except for two patients who were previously diagnosed with OSA. One of the two patients received surgical treatment for OSA, and none of them had received CPAP. However, the AHI of the two patients was still as high as 28.5 and 22.2 times/h, respectively. Therefore, we still included the two patients in the trial group. A total of 71 patients $(49.7 \%)$ had a $\mathrm{pO}_{2}<80 \mathrm{mmHg}$, of which seven patients (4.9\%) had a $\mathrm{pO}_{2}<60 \mathrm{mmHg}$. In addition, the $\mathrm{pCO}_{2}$ and lactate levels of all the patients were within the normal range at admission. According to the latest SVS/STS classification system, we also counted the number of dissection process-involved zones. 
TABLE 1 | Baseline characteristics of the patients.

\begin{tabular}{|c|c|}
\hline Variable & No. or mean (\%) \\
\hline \multicolumn{2}{|l|}{ Demographic characteristics } \\
\hline Male & $115(80.4)$ \\
\hline Age, years & $52.0 \pm 11.7$ \\
\hline Young adults $(>18, \leq 45)$ & $37(25.9)$ \\
\hline Middle-aged adults (>45, <60) & $68(47.6)$ \\
\hline Older adults ( $\geq 60)$ & $38(26.6)$ \\
\hline Patients with OSA & $92(64.3)$ \\
\hline Mild OSA & $38(26.6)$ \\
\hline Moderate OSA & $27(18.9)$ \\
\hline Severe OSA & $27(18.9)$ \\
\hline $\mathrm{BMI}\left(\mathrm{kg} / \mathrm{m}^{2}\right)$ & $26.8 \pm 4.1$ \\
\hline Hypertension & $107(74.8)$ \\
\hline Diabetes & $5(3.5)$ \\
\hline History of cardiovascular disease & $8(5.6)$ \\
\hline Smoking & $71(49.7)$ \\
\hline AHI (times/h) & $15.1 \pm 15.5$ \\
\hline \multicolumn{2}{|l|}{ Arterial blood gas analysis } \\
\hline $\mathrm{PH}$ & $7.42 \pm 0.03$ \\
\hline $\mathrm{pCO}_{2}(\mathrm{mmHg})$ & $38.7 \pm 3.4$ \\
\hline $\mathrm{pO}_{2}(\mathrm{mmHg})$ & $82.0 \pm 15.3$ \\
\hline Lactate (mmol/L) & $1.37 \pm 0.56$ \\
\hline \multicolumn{2}{|l|}{ Contrast-enhanced CT data } \\
\hline $\begin{array}{l}\text { Maximum aortic diameter at } \\
\text { onset }(\mathrm{mm})\end{array}$ & $39.2 \pm 4.5$ \\
\hline$\geq 40 \mathrm{~mm}$ & $63(44.1)$ \\
\hline$<40 \mathrm{~mm}$ & $80(55.9)$ \\
\hline $\begin{array}{l}\text { Maximum diameter of the } \\
\text { descending aorta }(\mathrm{mm})\end{array}$ & $39.7 \pm 4.8$ \\
\hline $\begin{array}{l}\text { FL diameter of the proximal } \\
\text { descending aorta }(\mathrm{mm})\end{array}$ & $18.8 \pm 5.9$ \\
\hline$\geq 22 \mathrm{~mm}$ & $50(35.5)$ \\
\hline$<22$ mm & $91(64.5)$ \\
\hline $\begin{array}{l}\text { Diameter of the distal aortic arch } \\
(\mathrm{mm})\end{array}$ & $31.5 \pm 3.9$ \\
\hline $\begin{array}{l}\text { Diameter of the descending } \\
\text { aorta at the level of the main } \\
\text { pulmonary artery (mm) }\end{array}$ & $34.6 \pm 4.7$ \\
\hline Maximum diameter of FL (mm) & $20.6 \pm 6.0$ \\
\hline \multicolumn{2}{|l|}{ False lumen status } \\
\hline Partially thrombosed & $79(55.2)$ \\
\hline Patent & $37(25.9)$ \\
\hline Completely thrombosed & 27 (18.9) \\
\hline Fusiform index & $0.60 \pm 0.04$ \\
\hline$\geq 0.64$ & $22(15.4)$ \\
\hline$<0.64$ & $121(85.6)$ \\
\hline $\begin{array}{l}\text { Numbers of dissection } \\
\text { process-involved zones }\end{array}$ & $7.8 \pm 2.0$ \\
\hline
\end{tabular}

The clinical characteristics and imaging data of all the patients are shown in Table 1.

The prevalence of OSA in TBAD patients was 64.3\%: 38 patients $(26.6 \%)$ had mild OSA, 27 (18.9\%) had moderate OSA,
TABLE 2 | Characteristics of the TBAD patients with and without OSA.

\begin{tabular}{|c|c|c|c|}
\hline Variable & $\begin{array}{l}\text { Patients } \\
\text { without OSA } \\
\quad(n=51)\end{array}$ & $\begin{array}{l}\text { Patients with } \\
\text { OSA } \\
(n=92)\end{array}$ & $p$-value \\
\hline Male, $n(\%)$ & $39(76.5)$ & $76(82.6)$ & 0.38 \\
\hline Age, years & $51.4 \pm 11.2$ & $52.3 \pm 12.1$ & 0.67 \\
\hline $\mathrm{BMI}\left(\mathrm{kg} / \mathrm{m}^{2}\right)$ & $24.7 \pm 3.2$ & $28.0 \pm 4.1$ & $<0.001$ \\
\hline Hypertension, $n(\%)$ & $37(72.5)$ & $70(76.1)$ & 0.64 \\
\hline Smoking, $n(\%)$ & $26(51.0)$ & $45(48.9)$ & 0.81 \\
\hline $\mathrm{AHI}($ times/h) & $2.8 \pm 1.4$ & $22.0 \pm 15.5$ & $<0.001$ \\
\hline $\begin{array}{l}\text { Maximum aortic diameter at onset } \\
(\mathrm{mm})\end{array}$ & $37.3 \pm 3.9$ & $40.3 \pm 4.5$ & $<0.001$ \\
\hline $\begin{array}{l}\text { Maximum aortic diameter at onset } \\
\geq 40 \mathrm{~mm}, n \text { (\%) }\end{array}$ & $13(25.5)$ & $50(54.3)$ & $<0.001$ \\
\hline $\begin{array}{l}\text { Maximum diameter of the } \\
\text { descending aorta }(\mathrm{mm})\end{array}$ & $38.2 \pm 4.9$ & $40.5 \pm 4.5$ & $0.029^{\star}$ \\
\hline $\begin{array}{l}\text { FL diameter of the proximal } \\
\text { descending thoracic aorta (mm) }\end{array}$ & $16.0 \pm 6.8$ & $20.3 \pm 4.7$ & $<0.001$ \\
\hline $\begin{array}{l}F L \text { diameter of the proximal } \\
\text { descending thoracic aorta } \geq 22 \mathrm{~mm} \text {, } \\
n(\%)\end{array}$ & $11(21.6)$ & $39(42.4)$ & 0.012 \\
\hline $\begin{array}{l}\text { Diameter of the distal aortic arch } \\
(\mathrm{mm})\end{array}$ & $30.4 \pm 3.4$ & $31.9 \pm 3.3$ & 0.008 \\
\hline $\begin{array}{l}\text { Diameter of the descending aorta at } \\
\text { the level of the main pulmonary } \\
\text { artery }(\mathrm{mm})\end{array}$ & $33.7 \pm 5.3$ & $35.0 \pm 4.3$ & $0.045^{\star}$ \\
\hline Maximum diameter of the FL (mm) & $18.8 \pm 7.5$ & $21.6 \pm 4.7$ & 0.018 \\
\hline Fusiform index & $0.597 \pm 0.04$ & $0.600 \pm 0.04$ & 0.287 \\
\hline Fusiform index $\geq 0.64, n(\%)$ & $6(11.8)$ & $16(17.4)$ & 0.372 \\
\hline Partially thrombosed, $n$ (\%) & $20(39.2)$ & $59(64.1)$ & 0.004 \\
\hline $\begin{array}{l}\text { Numbers of dissection } \\
\text { process-involved zones }\end{array}$ & $7.4 \pm 2.2$ & $8.1 \pm 1.8$ & $0.065^{\star}$ \\
\hline
\end{tabular}

*This variable was analyzed with the Mann-Whitney U-test.

and $27(18.9 \%)$ had severe OSA. TBAD patients with OSA showed a higher BMI of $28.0 \pm 4.1 \mathrm{~kg} / \mathrm{m}^{2}(\mathrm{p}<0.001)$ and a series of imaging differences. The main manifestation was aortic dilatation, which included the maximum aortic diameter at onset $(37.3 \pm 3.9$ vs. $40.3 \pm 4.5 \mathrm{~mm}, p<0.001)$, the proximal descending thoracic aorta FL diameter $(16.0 \pm 6.8$ vs. 20.3 $\pm 4.7 \mathrm{~mm}, p<0.001$ ), and the proportion of FL that was partially thrombosed (39.2 vs. $64.1 \%, p=0.004)$. Other imaging differences included the maximum diameter of the descending aorta ( $38.2 \pm 4.9$ vs. $40.5 \pm 4.5 \mathrm{~mm}, p=0.029)$, the diameter of the distal aortic arch $(30.4 \pm 3.4$ vs. $31.9 \pm 3.3 \mathrm{~mm}, p=$ $0.008)$, and the maximum diameter of the FL (18.8 \pm 7.5 vs. 21.6 $\pm 4.7 \mathrm{~mm}, p=0.018$ ). Two of the patients' FL were found in the abdominal aorta; therefore, we excluded these patients when analyzing the association between OSA status and the diameter of the FL of the proximal descending aorta. The characteristics of the TBAD patients with and without OSA are shown in Table 2.

\section{Association Between OSA Status and the Maximum Aortic Diameter at Onset}

As shown in Figure 2A, compared with patients without OSA, patients with OSA showed larger aortic diameters. Table 3 


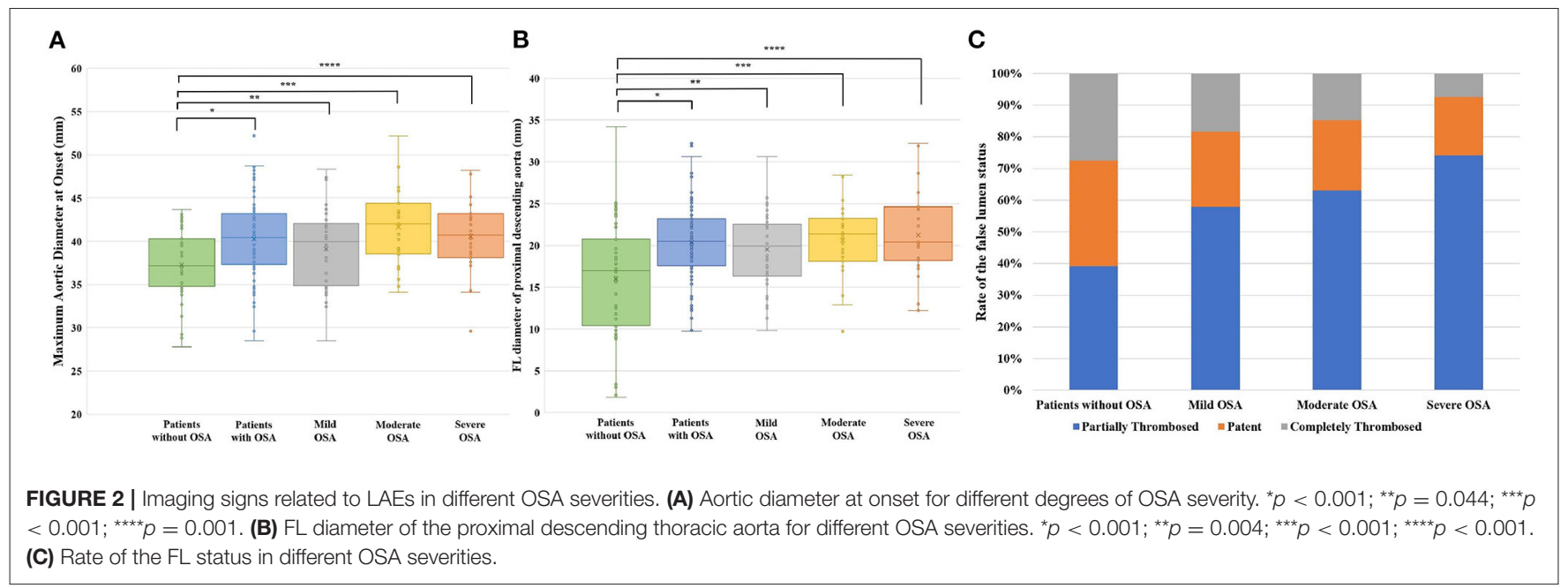

TABLE 3 | Univariate and multivariate logistic analyses of imaging signs related to LAEs.

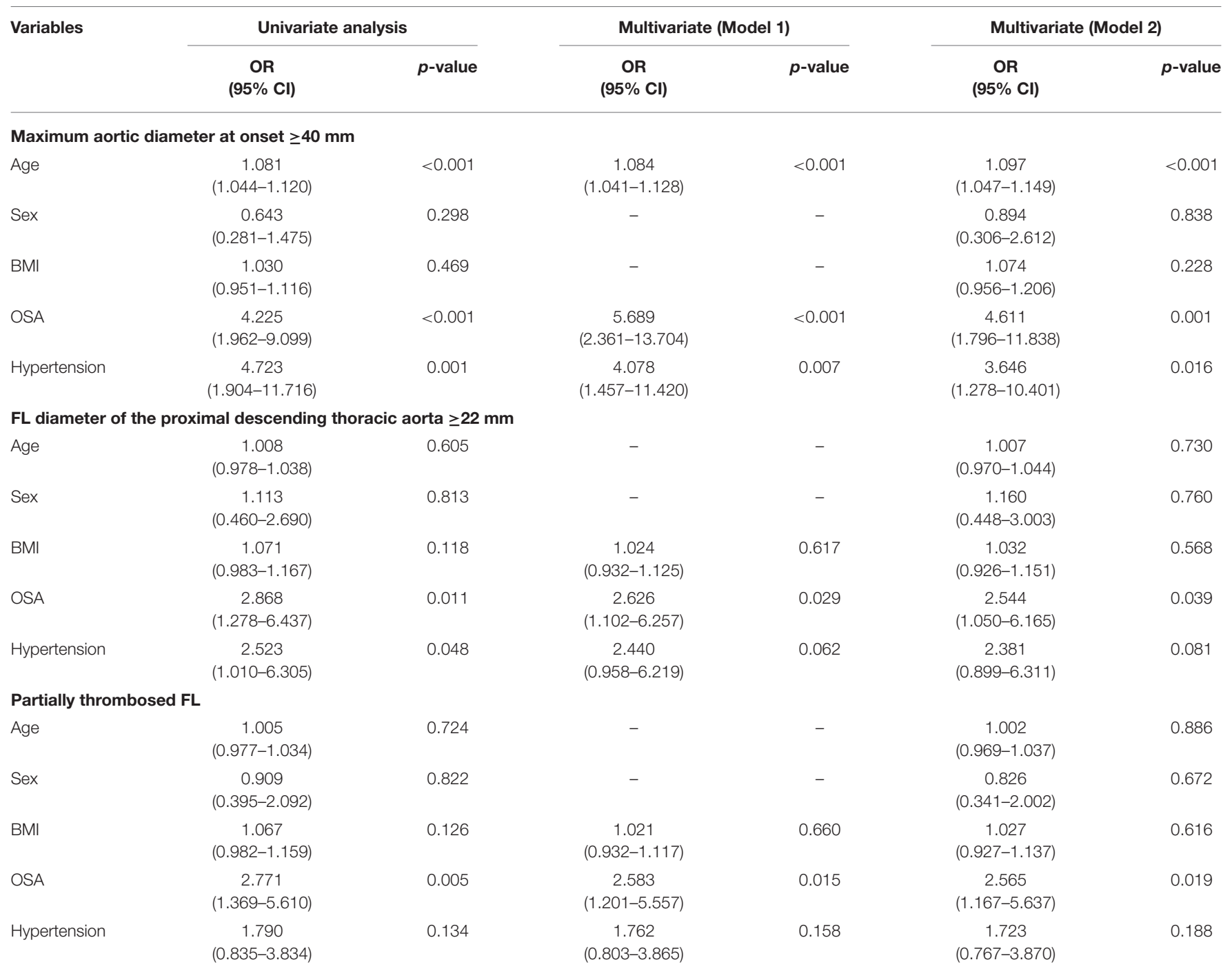


TABLE 4 | Logistic regression and trend analyses of imaging signs related to LAEs for different OSA severities.

\begin{tabular}{|c|c|c|c|}
\hline \multirow[t]{2}{*}{ OSA severity classification } & \multicolumn{3}{|c|}{ OR $(95 \% \mathrm{Cl}) p$-value } \\
\hline & Non-adjusted & Model $1^{\star}$ & Model $2^{\star \star}$ \\
\hline \multicolumn{4}{|c|}{ Maximum aortic diameter at onset $\geq 40 \mathrm{~mm}$} \\
\hline Non-OSA & Reference & Reference & Reference \\
\hline Mild OSA & $5.381(2.083-13.902) 0.001$ & 4.665 (1.650-13.191) 0.004 & $4.189(1.454-12.071) 0.008$ \\
\hline Moderate OSA & $7.380(2.616-20.817)<0.001$ & 8.157 (2.469-26.941) 0.001 & $6.684(1.933-23.107) 0.003$ \\
\hline Severe OSA & $5.125(1.836-14.308) 0.002$ & $6.489(2.056-20.481) 0.001$ & $4.830(1.387-16.824) 0.013$ \\
\hline$P$ for trend & $<0.001$ & $<0.001$ & 0.006 \\
\hline \multicolumn{4}{|c|}{ FL diameter of the proximal descending thoracic aorta $\geq 22 \mathrm{~mm}$} \\
\hline Non-OSA & Reference & Reference & Reference \\
\hline Mild OSA & $3.106(1.171-8.237) 0.023$ & $2.810(1.042-7.574) 0.041$ & $2.792(1.019-7.646) 0.046$ \\
\hline Moderate OSA & $3.644(1.279-10.386) 0.016$ & $3.301(1.121-9.719) 0.030$ & $3.207(1.050-9.793) 0.041$ \\
\hline Severe OSA & $3.644(1.279-10.386) 0.016$ & $2.733(0.867-8.620) 0.086$ & $2.669(0.835-8.530) 0.098$ \\
\hline$P$ for trend & 0.011 & 0.060 & 0.079 \\
\hline \multicolumn{4}{|l|}{ Partially thrombosed FL } \\
\hline Non-OSA & Reference & Reference & Reference \\
\hline Mild OSA & $2.131(0.907-5.010) 0.083$ & $2.111(0.877-5.081) 0.096$ & $2.067(0.846-5.052) 0.111$ \\
\hline Moderate OSA & 2.635 (1.007-6.898) 0.048 & 2.763 (1.006-7.591) 0.049 & 2.775 (0.971-7.933) 0.057 \\
\hline Severe OSA & 4.429 (1.584-12.380) 0.005 & 4.207 (1.286-13.766) 0.018 & 4.228 (1.282-13.945) 0.018 \\
\hline$P$ for trend & 0.003 & 0.010 & 0.011 \\
\hline
\end{tabular}

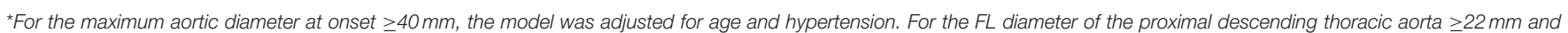
partially thrombosed FL, the model was adjusted for BMI and hypertension; **Adjusted for age, hypertension, sex, and BMI.

displays the results for the univariate and multivariate logistic regression analyses on a maximum aortic diameter at onset $\geq 40 \mathrm{~mm}$. The risk of an aortic diameter larger than $40 \mathrm{~mm}$ in TBAD patients with OSA was $\sim 4$ times higher (OR: 4.225, 95\% CI: 1.962-9.099, $p<0.001)$ than that in patients without OSA. After adjusting for age and hypertension (model 1) and for age, hypertension, sex, and BMI (model 2), the ORs were 5.689 (95\% CI: 2.361-13.704, $p<0.001$ ) and 4.611 (95\% CI: $1.796-11.838, p=0.001)$, respectively. We also analyzed the effect of different OSA severities on the aortic diameter, as shown in Table 4. After adjusting for all the relevant factors (model 2 ), the ORs for patients with mild, moderate and severe OSA were 4.189 (95\% CI: 1.454-12.071, $p=0.008$ ), 6.684 (95\% CI: 1.933-23.107, $p=0.003$ ), and 4.830 (95\% CI: $1.387-16.824, p$ $=0.013$ ), respectively. Trend analysis showed that the risk of an aortic diameter $\geq 40 \mathrm{~mm}$ increased with increasing OSA severity $(p=0.006$; Table 4).

\section{Association Between OSA Status and the FL Diameter of the Proximal Descending Aorta}

TBAD patients with OSA showed a larger proximal descending aorta FL diameter (Table 2). As OSA severity increased, the FL diameter also increased gradually (Figure 2B), but for a proximal descending aorta $\mathrm{FL} \geq 22 \mathrm{~mm}$ in different OSA severities, as shown in Table 4, a trend analysis did not show a significant increase in OSA severity $(p=0.079)$. Univariate logistic regression showed that age, sex, and BMI were not risk factors for dilatation of the proximal descending aorta FL $(\geq 22 \mathrm{~mm})$. However, OSA was a significant risk factor (OR:
2.868, 95\% CI: $1.278-6.437, p=0.011)$ for FL dilatation. After adjusting for all the relevant factors (age, hypertension, sex, and BMI), the OR was 2.544 (95\% CI: 1.050-6.165, $p=0.039$; Table 3).

\section{Association Between OSA Status and Thrombosed FL}

Most of the patients had partially thrombosed FLs. However, the proportion of partially thrombosed FLs in severe OSA patients was as high as $74.1 \%$, which was much higher than that in patients without OSA (39.2\%) $\left(p=0.004, \chi^{2}=8.238\right)$. The proportions of patients with mild and moderate OSA were 57.9 and $63.0 \%$, respectively (Table 5). Univariate and multivariate logistic regression analyses on partially thrombosed FL are shown in Table 3. After adjusting for confounding factors, the ORs of OSA for model 1 and model 2 were 2.583 (95\% CI: $1.201-$ 5.557, $p=0.015$ ) and 2.565 (95\% CI: 1.167-5.637, $p=0.019$ ), respectively. Figure $\mathbf{2 C}$ shows the rate of the FL status in different OSA severities. Trend analysis showed that the risk of a partially thrombosed FL increased with increasing OSA severity ( $p=$ 0.011; Table 4).

\section{Other Imaging Differences Between TBAD Patients With and Without OSA}

As shown in Figure 3, other significant imaging differences between the two groups included the maximum diameter of the descending aorta (38.2 \pm 4.9 vs. $40.5 \pm 4.5 \mathrm{~mm}, p=0.029)$, the diameter of the distal aortic arch $(30.4 \pm 3.4$ vs. $31.9 \pm 3.3 \mathrm{~mm}$, $p=0.008)$, and the maximum diameter of the FL ( $18.8 \pm 7.5 \mathrm{vs.}$ $21.6 \pm 4.7 \mathrm{~mm}, p=0.018)$. We further analyzed these imaging 
TABLE 5 | Thrombosed FL with different OSA severity levels.

\begin{tabular}{|c|c|c|c|c|c|c|}
\hline \multirow[t]{2}{*}{ Variable } & \multirow{2}{*}{$\begin{array}{l}\text { Patients without OSA } \\
\qquad(n=51)\end{array}$} & \multicolumn{3}{|c|}{ Patients with OSA } & \multirow[t]{2}{*}{$p$-value } & \multirow[t]{2}{*}{$x^{2}$} \\
\hline & & $\begin{array}{l}\text { Mild OSA } \\
(n=38)\end{array}$ & $\begin{array}{l}\text { Moderate OSA } \\
\quad(n=27)\end{array}$ & $\begin{array}{c}\text { Severe OSA } \\
(n=27)\end{array}$ & & \\
\hline Partially thrombosed & $\begin{array}{c}20 \\
(39.2 \%)\end{array}$ & $\begin{array}{c}22 \\
(57.9 \%)\end{array}$ & $\begin{array}{c}17 \\
(63.0 \%)\end{array}$ & $\begin{array}{c}20 \\
(74.1 \%)\end{array}$ & 0.004 & 8.238 \\
\hline Patent & $\begin{array}{c}17 \\
(33.3 \%)\end{array}$ & $\begin{array}{c}9 \\
(23.7 \%)\end{array}$ & $\begin{array}{c}6 \\
(22.2 \%)\end{array}$ & $\begin{array}{c}5 \\
(18.5 \%)\end{array}$ & 0.129 & 2.300 \\
\hline
\end{tabular}

differences according to OSA severity and found that the most significant difference was between non-OSA patients and patients with moderate and severe OSA.

\section{DISCUSSION}

To our knowledge, this is the first study to find that TBAD patients with OSA have a higher risk of aortic dilatation and that some of the imaging differences are related to LAEs.

This case-control study included 143 TBAD patients, and the prevalence of OSA was as high as $64.3 \%$. In 2003, Sampol et al. (46) first found a correlation between OSA and aortic dissection, and an increasing number of studies have shown that OSA is an independent risk factor for $\mathrm{AD}$, especially for TBAD patients with moderate to severe OSA (47-49). Previous studies have indicated that OSA may lead to dilatation of the aorta, including the aortic root (52-55), thoracic aorta (56) and abdominal aorta (57); other studies have come to the opposite conclusion (58), and most of the OSA patients in these studies had no history of cardiovascular disease. However, the effect of OSA on vascular morphology changes in TBAD has rarely been reported. As seen in our results, the main change in the aorta for TBAD patients with OSA is aortic dilatation, which also includes enlargement of the FL. The mechanism of aortic dilatation and the development of TBAD induced by OSA has not been fully elucidated. The possible mechanism includes changes in intrathoracic pressure, meaning that the increase in pleural negative pressure can lead to mechanical stretch of the aorta $(54,55,59-61)$, which further leads to the expansion of the aortic root, thoracic aorta and thoracic FL; patients with frequent intermittent hypoxia leading to oxidative stress and increases in sympathetic activity exhibit an increase in blood pressure due to the activation of the renin-angiotensin-aldosterone system $(59,60,62)$. The state of chronic intermittent hypoxemia and the altered microenvironment in OSA patients, such as the increase in IL-6 levels and reduction in TGF- $\beta$ levels, could damage the function of endothelial cells and promote a Th17/Treg imbalance, which leads to a reduction in the production of endotheliumdependent vasodilator substances and contributes to vascular dysfunction and stimulation of systemic inflammation (63-67).

Another important finding in our study showed that vascular changes in TBAD patients with OSA were related to the predictors of LAEs, which included an initial aortic diameter $\geq 40 \mathrm{~mm}$, a FL diameter of the proximal descending thoracic aortic $\geq 22 \mathrm{~mm}$, and a partially thrombosed FL. Previous studies have proven that the postdischarge mortality of patients with these factors will be substantially increased $(10,15,20,21,23-$ 25). An aortic diameter $>40 \mathrm{~mm}$ and a FL diameter $>22 \mathrm{~mm}$ have been suggested as high-risk features by SVS/STS research (50). Our results indicate that for patients with OSA, the risk of these imaging signs was several times higher than that of non-OSA patients. Univariate analysis revealed that the risk of aortic diameter dilation larger than $40 \mathrm{~mm}$ in OSA patients was $\sim 4.6$ times higher than that in non-OSA patients when we adjusted for age, sex, BMI, and hypertension in the multivariate analysis. In addition, age is an independent risk factor for aortic enlargement in TBAD patients, which suggests that the degree of aortic dilatation is more obvious in elderly TBAD patients with OSA.

In addition, we observed the effect of OSA on the size and thrombosis of the FL. Song et al. (24) revealed that patients with an FL diameter of the initial upper descending thoracic aorta $\geq 22 \mathrm{~mm}$ showed a higher rate of aortic adverse events such as aneurysmal dilation or aortic-related death. From the results, the risk of a proximal descending aortic FL larger than $22 \mathrm{~mm}$ was $\sim 2.5$ times higher in OSA patients than in non-OSA patients after adjusting for other relevant factors (model 2). This suggests that OSA is an important factor related to the prognosis of TBAD patients. Our study shows that OSA is an important factor leading to an increased risk of partial FL thrombosis. Wang et al. (41) came to the same conclusion. The results showed that the risk of FL thrombosis in patients with OSA is increased by $\sim 2.5$-fold and that the proportion of FL thrombosis increases with the severity of OSA. Patients with OSA are in a state of chronic intermittent hypoxemia, which may lead to endothelial cell damage and the release of inflammatory factors, causing hypercoagulability of blood. This process increases the chance of FL thrombosis and is accompanied by intrathoracic pressure fluctuations, which leads to changes in aortic transmural pressure and mechanical stretching of the aorta. Furthermore, it may interfere with thrombosis of the FL, and both processes eventually cause a higher probability of partial thrombosis.

We classified OSA according to its severity as mild, moderate and severe. As seen in our results, moderate OSA patients showed a higher OR than severe and mild OSA patients in the logistic regression analyses on an aortic diameter 


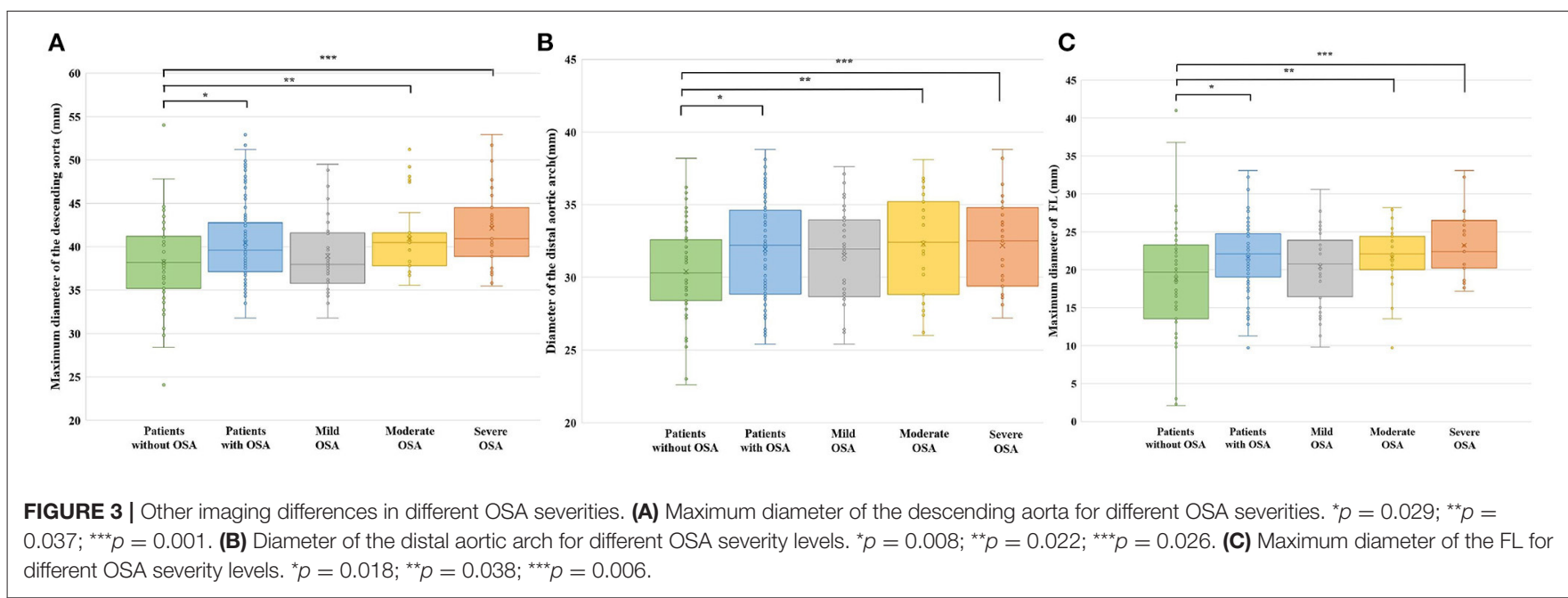

$\geq 40 \mathrm{~mm}$. This may be due to the sampling error caused by the relatively small sample size after grouping or other unknown factors in moderate OSA. Most of the vascular morphology differences were reflected in the patients with moderate and severe OSA, including the aortic diameter at onset, the maximum diameter of the descending aorta, the diameter of the distal aortic arch, and the maximum diameter of the FL. Moderate to severe OSA has a significant effect on morphological changes in the aorta. Furthermore, TBAD patients with moderate to severe OSA may have a worse prognosis.

We also measured other vascular morphological parameters correlated with prognosis that were reported by previous studies, including the fusiform index (29), but there was no significant difference between OSA and non-OSA in TBAD patients. This is because the fusiform index was defined to express the dilatation degree of the descending aorta, which is a method used to describe the morphological changes in the aorta by local dilation. However, our study found that patients with OSA tend to present dilation of the whole aorta, which may explain why there was no significant difference in the degree of local expansion between OSA and nonOSA patients. We used the SVS/STS classification system to describe the extent of FL involvement. There was no significant difference between OSA and non-OSA, which shows that although OSA can lead to enlargement of the FL, it cannot lead to extension of the FL. The SVS/STS classification system also provides a way for us to further study the area of dissection involved.

From the blood gas analysis results, nearly half of the patients had a decrease in $\mathrm{pO}_{2}$, of which 7 patients reached type I respiratory failure. We considered that this is an acute manifestation rather than a chronic progressive condition because when taking the patients' medical history, we found that almost all patients with decreased $\mathrm{pO}_{2}$ complained of dyspnoea and sweating caused by pain, and when we rechecked the blood gas before discharge, it had returned to the normal range.
The strengths of our study include that this is the first study to explore the effect of OSA on vascular morphological changes in TBAD patients and the first to identify OSA as an independent risk factor related to LAEs. To comprehensively and systematically assess changes in the aorta, we included up to nine indicators, including not only aortic dilatation, FL status, and imaging signs with LAEs but also the dissection process-involved zones according to the SVS/STS classification system. We first found that the effect of OSA on the aorta was mainly manifested as aortic dilation rather than an increase in the involved zones. There are still some limitations to our study, which include the need for further investigations in animal experiments to reveal the molecular mechanism of the occurrence and development of TBAD caused by OSA. Further studies on the prognosis of TBAD patients with OSA are also needed.

\section{CONCLUSION}

TBAD patients with OSA, especially moderate to severe OSA, have vascular morphological changes in the different regions of the aorta that mainly manifest as aortic dilation. OSA was an independent risk factor for a maximum aortic diameter at onset $\geq 40 \mathrm{~mm}$, an FL diameter in the proximal descending aorta $\geq 22 \mathrm{~mm}$, and a partially thrombosed FL. The imaging differences related to LAEs suggest that OSA is an important factor that affects the prognosis of TBAD patients.

\section{DATA AVAILABILITY STATEMENT}

The original contributions presented in the study are included in the article/supplementary material, further inquiries can be directed to the corresponding author/s.

\section{ETHICS STATEMENT}

The studies involving human participants were reviewed and approved by the Medical Research Ethics Committee of the First 
Hospital of China Medical University. The patients/participants provided their written informed consent to participate in this study.

\section{AUTHOR CONTRIBUTIONS}

JiawZ and SX first conceived this article, and designed the research method of this study. JiawZ was responsible for data analysis and writing the manuscript, collected the medical records, and imaging data as well as drafted the manuscript. ZZ and YY also collected the medical records and performed sleep monitoring. LW and HW drafted the discussion. LF and BZ gave the help of statistical analysis. WW and JianZ participated in the design of the study and

\section{REFERENCES}

1. Pape LA, Awais M, Woznicki EM, Suzuki T, Trimarchi S, Evangelista A, et al. Presentation, diagnosis, and outcomes of acute aortic dissection: 17year trends from the international registry of acute aortic dissection. J Am Coll Cardiol. (2015) 66:350-8. doi: 10.1016/j.jacc.2015.05.029

2. Nienaber CA, Clough RE. Management of acute aortic dissection. Lancet. (2015) 385:800-11. doi: 10.1016/S0140-6736(14)61005-9

3. Beller CJ, Labrosse MR, Thubrikar MJ, Robicsek F. Role of aortic root motion in the pathogenesis of aortic dissection. Circulation. (2004) 109:7639. doi: 10.1161/01.CIR.0000112569.27151.F7

4. Hagan PG, Nienaber CA, Isselbacher EM, Bruckman D, Karavite DJ, Russman PL, et al. The International Registry of Acute Aortic Dissection (IRAD): new insights into an old disease. JAMA. (2000) 283:897903. doi: 10.1001/jama.283.7.897

5. Sampson UK, Norman PE, Fowkes FG, Aboyans V, Yanna S, Harrell FE, et al., et al. Global and regional burden of aortic dissection and aneurysms: mortality trends in 21 world regions, 1990 to 2010. Glob Heart. (2014) 9:171-80.e10. doi: 10.1016/j.gheart.2013.12.010

6. Erbel R, Aboyans V, Boileau C, Bossone E, Bartolomeo RD, Eggebrecht H, et al. 2014 ESC Guidelines on the diagnosis and treatment of aortic diseases: document covering acute and chronic aortic diseases of the thoracic and abdominal aorta of the adult. The Task Force for the Diagnosis and Treatment of Aortic Diseases of the European Society of Cardiology (ESC). Eur Heart J. (2014) 35:2873-926. doi: 10.1093/eurheartj/ehu281

7. Hughes GC. Management of acute type B aortic dissection; ADSORB trial. $J$ Thorac Cardiovasc Surg. (2015) 149:S158-S62. doi: 10.1016/j.jtcvs.2014.08.083

8. Luebke T, Brunkwall J. Type B aortic dissection: a review of prognostic factors and meta-analysis of treatment options. Aorta (Stamford). (2014) 2:265-78. doi: 10.12945/j.aorta.2014.14-040

9. Evangelista A, Isselbacher EM, Bossone E, Gleason TG, Eusanio MD, Sechtem $\mathrm{U}$, et al. Insights from the international registry of acute aortic dissection: a 20-year experience of collaborative clinical research. Circulation. (2018) 137:1846-60. doi: 10.1161/CIRCULATIONAHA.117.031264

10. Schwartz SI, Durham C, Clouse WD, Patel VI, Lancaster RT, Cambria RP, et al. Predictors of late aortic intervention in patients with medically treated type B aortic dissection. J Vasc Surg. (2018) 67:78-84. doi: 10.1016/j.jvs.2017. 05.128

11. Qin YL, Deng G, Li TX, Wang W, Teng GJ. Treatment of acute type-B aortic dissection: thoracic endovascular aortic repair or medical management alone? JACC Cardiovasc Interv. (2013) 6:185-91. doi: 10.1016/j.jcin.2012. 11.004

12. Durham CA, Cambria RP, Wang LJ, Ergul EA, Aranson NJ, Patel VI, et al. The natural history of medically managed acute type B aortic dissection. J Vasc Surg. (2015) 61:1192-8. doi: 10.1016/j.jvs.2014.12.038

13. Conway AM, Sadek M, Lugo J, Pillai JB, Pellet Y, Panagopoulos G, et al. Outcomes of open surgical repair for chronic type B aortic dissections. J Vasc Surg. (2014) 59:1217-23. doi: 10.1016/j.jvs.2013.11.002 analyzed sleep monitoring data. SX carried out critical revision and finalization of the manuscript. All authors approved the final manuscript.

\section{FUNDING}

This work was supported by the National Natural and Science Foundation of China (Grant Numbers: 81974049).

\section{ACKNOWLEDGMENTS}

The authors would like to thank Yidu Cloud (Beijing) Technology Co., Ltd., for their assistance in data searching, extraction, and processing.

14. Kaji S. Update on the therapeutic strategy of type B aortic dissection. J Atheroscler Thromb. (2018) 25:203-12. doi: 10.5551/jat.RV17017

15. Matsushita A, Hattori T, Tsunoda Y, Sato Y, Mihara W. Impact of initial aortic diameter and false-lumen area ratio on Type B aortic dissection prognosis. Interact Cardiovasc Thorac Surg. (2018) 26:176-82. doi: 10.1093/icvts/ivx286

16. Matsushita A, Tabata M, Mihara W, Shimamoto T, Komiya T, Takanashi S, et al. Risk score system for late aortic events in patients with uncomplicated type B aortic dissection. J Thorac Cardiovasc Surg. (2020) 159:217383.e1. doi: 10.1016/j.jtcvs.2019.06.019

17. Higashigaito K, Sailer AM, van Kuijk SMJ, Willemink MJ, Hahn LD, Hastie TJ, et al. Aortic growth and development of partial false lumen thrombosis are associated with late adverse events in type B aortic dissection. J Thorac Cardiovasc Surg. (2021) 161:1184-90.e2. doi: 10.1016/j.jtcvs.2019. 10.074

18. Wu J, Zafar MA, Li Y, Saeyeldin A, Huang Y, Zhao R, et al. Ascending aortic length and risk of aortic adverse events: the neglected dimension. J Am Coll Cardiol. (2019) 74:1883-94. doi: 10.1016/j.jacc.2019.07.078

19. Sailer AM, van Kuijk SM, Nelemans PJ, Chin AS, Kino A, Huininga M, et al. Computed tomography imaging features in acute uncomplicated Stanford type-B aortic dissection predict late adverse events. Circ Cardiovasc Imaging. (2017) 10:e005709. doi: 10.1161/CIRCIMAGING.116.005709

20. Kudo T, Mikamo A, Kurazumi H, Suzuki R, Morikage N, Hamano K Predictors of late aortic events after Stanford type B acute aortic dissection. J Thorac Cardiovasc Surg. (2014) 148:98-104. doi: 10.1016/j.jtcvs.2013.07.047

21. Onitsuka S, Akashi H, Tayama K, Okazaki T, Ishihara K, Hiromatsu $\mathrm{S}$, et al. Long-term outcome and prognostic predictors of medically treated acute type B aortic dissections. Ann Thorac Surg. (2004) 78:126873. doi: 10.1016/j.athoracsur.2004.02.031

22. Jonker FH, Trimarchi S, Rampoldi V, Patel HJ, O'Gara P, Peterson MD, et al. Aortic expansion after acute type B aortic dissection. Ann Thorac Surg. (2012) 94:1223-9. doi: 10.1016/j.athoracsur.2012.05.040

23. Winnerkvist A, Lockowandt U, Rasmussen E, Rådegran K. A prospective study of medically treated acute type B aortic dissection. Eur J Vasc Endovasc Surg. (2006) 32:349-55. doi: 10.1016/j.ejvs.2006.04.004

24. Song JM, Kim SD, Kim JH, Kim MJ, Kang DH, Seo JB, et al. Long-term predictors of descending aorta aneurysmal change in patients with aortic dissection. J Am Coll Cardiol. (2007) 50:799-804. doi: 10.1016/j.jacc.2007.03.064

25. Tsai TT, Evangelista A, Nienaber CA, Myrmel T, Meinhardt G, Cooper JV, et al. Partial thrombosis of the false lumen in patients with acute type B aortic dissection. N Engl J Med. (2007) 357:349-59. doi: 10.1056/NEJMoa0 63232

26. Trimarchi S, Tolenaar JL, Jonker FH, Murray B, Tsai TT, Eagle KA, et al. Importance of false lumen thrombosis in type B aortic dissection prognosis. $J$ Thorac Cardiovasc Surg. (2013) 145:S208-S12. doi: 10.1016/j.jtcvs.2012.11.048

27. Ueki C, Sakaguchi G, Shimamoto T, Komiya T. Prognostic factors in patients with uncomplicated acute type B aortic dissection. Ann Thorac Surg. (2014) 97:767-73; discussion 773. doi: 10.1016/j.athoracsur.2013.10.038 
28. Li D, Ye L, He Y, Cao X, Liu J, Zhong W, et al. False lumen status in patients with acute aortic dissection: a systematic review and meta-analysis. J Am Heart Assoc. (2016) 5:e003172. doi: 10.1161/JAHA.115.003172

29. Marui A, Mochizuki T, Koyama T, Mitsui N. Degree of fusiform dilatation of the proximal descending aorta in type B acute aortic dissection can predict late aortic events. I Thorac Cardiovasc Surg. (2007) 134:116370. doi: 10.1016/j.jtcvs.2007.07.037

30. Kitai T, Kaji S, Yamamuro A, Tani T, Kinoshita M, Ehara N, et al. Impact of new development of ulcer-like projection on clinical outcomes in patients with type B aortic dissection with closed and thrombosed false lumen. Circulation. (2010) 122:S74-S80. doi: 10.1161/CIRCULATIONAHA.109.9 27517

31. Kaji S, Akasaka T, Katayama M, Yamamuro A, Yamabe $\mathrm{K}$, Tamita K, et al. Long-term prognosis of patients with type B aortic intramural hematoma. Circulation. (2003) 108(Suppl. 1):II307-II11. doi: 10.1161/01.cir.0000087425.86049.74

32. Sueyoshi E, Sakamoto I, Hayashi $K$, Yamaguchi $T$, Imada T. Growth rate of aortic diameter in patients with type B aortic dissection during the chronic phase. Circulation. (2004) 110:II256-II61. doi: 10.1161/01.CIR.0000138386.48852.b6

33. Tolenaar JL, van Keulen JW, Jonker FH, van Herwaarden JA, Verhagen HJ, Moll FL, et al. Morphologic predictors of aortic dilatation in type B aortic dissection. J Vasc Surg. (2013) 58:1220-5. doi: 10.1016/j.jvs.2013. 05.031

34. Kodama K, Nishigami K, Sakamoto T, Sawamura T, Hirayama T, Misumi $\mathrm{H}$, et al. Tight heart rate control reduces secondary adverse events in patients with type B acute aortic dissection. Circulation. (2008) 118:S167S70. doi: 10.1161/CIRCULATIONAHA.107.755801

35. Evangelista A, Salas A, Ribera A, Ferreira-González I, Cuellar H, Pineda $\mathrm{V}$, et al. Long-term outcome of aortic dissection with patent false lumen: predictive role of entry tear size and location. Circulation. (2012) 125:313341. doi: 10.1161/CIRCULATIONAHA.111.090266

36. Kitada S, Akutsu K, Tamori Y, Yoshimuta T, Hashimoto H, Takeshita S. Usefulness of fibrinogen/fibrin degradation product to predict poor one-year outcome of medically treated patients with acute type B aortic dissection. Am J Cardiol. (2008) 101:1341-4. doi: 10.1016/j.amjcard.2007. 12.036

37. Sakakura K, Kubo N, Ako J, Wada H, Fujiwara N, Funayama $\mathrm{H}$, et al. Peak C-reactive protein level predicts long-term outcomes in type B acute aortic dissection. Hypertension. (2010) 55:422-9. doi: 10.1161/HYPERTENSIONAHA.109.143131

38. van Bogerijen GH, Tolenaar JL, Rampoldi V, Moll FL, van Herwaarden JA, Jonker FH, et al. Predictors of aortic growth in uncomplicated type B aortic dissection. J Vasc Surg. (2014) 59:1134-43. doi: 10.1016/j.jvs.2014. 01.042

39. Dempsey JA, Veasey SC, Morgan BJ, O’Donnell CP. Pathophysiology of sleep apnea. Physiol Rev. (2010) 90:47-112. doi: 10.1152/physrev.000 43.2008

40. Javaheri S, Barbe F, Campos-Rodriguez F, Dempsey JA, Khayat $\mathrm{R}$, Javaheri $\mathrm{S}$, et al. Sleep apnea: types, mechanisms, and clinical cardiovascular consequences. J Am Coll Cardiol. (2017) 69:841-58. doi: 10.1016/j.jacc.2016.11.069

41. Wang L, Chen J, Li G, Luo S, Wang R, Li W, et al. The prevalence of sleep apnea in type B aortic dissection: implications for false lumen thrombosis. Sleep. (2017) 40:zsw071. doi: 10.1093/sleep/zsw071

42. Zhang $\mathrm{X}$, Zhang $\mathrm{T}$, Zhang $\mathrm{X}$, Zhang $\mathrm{C}$, Chen J, Han $\mathrm{F}$, et al. Obstructive sleep apnea syndrome: a risk factor for Stanford's type B aortic dissection. Ann Vasc Surg. (2014) 28:1901-8. doi: 10.1016/j.avsg.2014. 07.014

43. Delsart P, Juthier F, Clough RE, Sobocinski J, Azzaoui R, Ramstein J, et al. Prognostic significance of sleep apnea syndrome on false lumen aortic expansion in post-acute aortic syndrome. Ann Thorac Surg. (2016) 102:155864. doi: 10.1016/j.athoracsur.2016.03.102

44. Heinzer R, Vat S, Marques-Vidal P, Marti-Soler H, Andries $\mathrm{D}$, Tobback N, et al. Prevalence of sleep-disordered breathing in the general population: the HypnoLaus study. Lancet Respir Med. (2015) 3:310-8. doi: $10.1016 / \mathrm{S} 2213-2600(15) 0$ 0043-0
45. Senaratna CV, Perret JL, Lodge CJ, Lowe AJ, Campbell BE, Matheson MC, et al. Prevalence of obstructive sleep apnea in the general population: a systematic review. Sleep Med Rev. (2017) 34:70-81. doi: 10.1016/j.smrv.2016.07.002

46. Sampol G, Romero O, Salas A, Tovar JL, Lloberes P, Sagalés T, et al. Obstructive sleep apnea and thoracic aorta dissection. Am J Respir Crit Care Med. (2003) 168:1528-31. doi: 10.1164/rccm.200304-566OC

47. Yanagi H, Imoto K, Suzuki S, Uchida K, Masuda M, Miyashita A. Acute aortic dissection associated with sleep apnea syndrome. Ann Thorac Cardiovasc Surg. (2013) 19:456-60. doi: 10.5761/atcs.oa.12.02014

48. Saruhara H, Takata Y, Usui Y, Shiina K, Hashimura Y, Kato K, et al. Obstructive sleep apnea as a potential risk factor for aortic disease. Heart Vessels. (2012) 27:166-73. doi: 10.1007/s00380-011-0135-3

49. Zhou X, Liu F, Zhang W, Wang G, Guo D, Fu W, et al. Obstructive sleep apnea and risk of aortic dissection: a meta-analysis of observational studies. Vascular. (2018) 26:515-23. doi: 10.1177/1708538118766102

50. Lombardi JV, Hughes GC, Appoo JJ, Bavaria JE, Beck AW, Cambria RP, et al. Society for Vascular Surgery (SVS) and Society of Thoracic Surgeons (STS) reporting standards for type B aortic dissections. J Vasc Surg. (2020) 71:723-47. doi: 10.1016/j.jvs.2019.11.013

51. Kapur VK, Auckley DH, Chowdhuri S, Kuhlmann DC, Mehra R, Ramar K, et al. Clinical practice guideline for diagnostic testing for adult obstructive sleep apnea: an American Academy of Sleep Medicine Clinical Practice Guideline. J Clin Sleep Med. (2017) 13:479-504. doi: 10.5664/jcsm.6506

52. Kohler M, Blair E, Risby P, Nickol AH, Wordsworth P, Forfar C, et al. The prevalence of obstructive sleep apnoea and its association with aortic dilatation in Marfan's syndrome. Thorax. (2009) 64:1626. doi: 10.1136/thx.2008.102756

53. Pedrosa RP, Drager LF, Genta PR, Amaro AC, Antunes MO, Matsumoto AY, et al. Obstructive sleep apnea is common and independently associated with atrial fibrillation in patients with hypertrophic cardiomyopathy. Chest. (2010) 137:1078-84. doi: 10.1378/chest.09-2335

54. Baguet JP, Minville C, Tamisier R, Roche F, Barone-Rochette G, Ormezzano $\mathrm{O}$, et al. Increased aortic root size is associated with nocturnal hypoxia and diastolic blood pressure in obstructive sleep apnea. Sleep. (2011) 34:16057. doi: $10.5665 /$ sleep. 1406

55. Stöwhas AC, Namdar M, Biaggi P, Russi EW, Bloch KE, Stradling JR, et al. The effect of simulated obstructive apnea and hypopnea on aortic diameter and BP. Chest. (2011) 140:675-80. doi: 10.1378/chest.10-2799

56. Serizawa N, Yumino D, Takagi A, Gomita K, Kajimoto K, Tsurumi $\mathrm{Y}$, et al. Obstructive sleep apnea is associated with greater thoracic aortic size. J Am Coll Cardiol. (2008) 52:885-6. doi: 10.1016/j.jacc.2008. 05.039

57. Tachikawa R, Hamada S, Azuma M, Toyama Y, Murase K, Tanizawa $\mathrm{K}$, et al. Impact of obstructive sleep apnea on abdominal aortic diameters. Am J Cardiol. (2014) 114:618-23. doi: 10.1016/j.amjcard.2014. 05.044

58. Meuleman C, Boccara F, Nguyen XL, Di Angelantonio E, Ederhy S, Janower $\mathrm{S}$, et al. Is the aortic root dilated in obstructive sleep apnoea syndrome? Arch Cardiovasc Dis. (2008) 101:391-7. doi: 10.1016/j.acvd.2008. 06.007

59. Cicek D, Lakadamyali H, Yagbasan BD, Sapmaz I, Müderrisoglu H. Obstructive sleep apnoea and its association with left ventricular function and aortic root parameters in newly diagnosed, untreated patients: a prospective study. J Int Med Res. (2011) 39:2228-38. doi: 10.1177/1473230011039 00619

60. Naito R, Sakakura K, Kasai T, Dohi T, Wada H, Sugawara Y, et al Aortic dissection is associated with intermittent hypoxia and reoxygenation. Heart Vessels. (2012) 27:265-70. doi: 10.1007/s00380-0110149-x

61. Clarenbach CF, Camen G, Sievi NA, Wyss C, Stradling JR, Kohler M. Effect of simulated obstructive hypopnea and apnea on thoracic aortic wall transmural pressures. J Appl Physiol (1985). (2013) 115:6137. doi: 10.1152 /japplphysiol.00439.2013

62. Somers VK, White DP, Amin R, Abraham WT, Costa F, Culebras A, et al. Sleep apnea and cardiovascular disease: an American Heart Association/american College Of Cardiology Foundation Scientific Statement from the American Heart Association Council for High Blood Pressure Research Professional Education Committee, Council on Clinical Cardiology, Stroke Council, and 
Council On Cardiovascular Nursing. In collaboration with the National Heart, Lung, and Blood Institute National Center on Sleep Disorders Research (National Institutes of Health). Circulation. (2008) 118:1080111. doi: 10.1161/CIRCULATIONAHA.107.189420

63. Hoyos CM, Melehan KL, Liu PY, Grunstein RR, Phillips CL. Does obstructive sleep apnea cause endothelial dysfunction? A critical review of the literature. Sleep Med Rev. (2015) 20:15-26. doi: 10.1016/j.smrv.2014. 06.003

64. Kato M, Roberts-Thomson P, Phillips BG, Haynes WG, Winnicki M, Accurso $\mathrm{V}$, et al. Impairment of endothelium-dependent vasodilation of resistance vessels in patients with obstructive sleep apnea. Circulation. (2000) 102:260710. doi: 10.1161/01.CIR.102.21.2607

65. Gjørup PH, Sadauskiene L, Wessels J, Nyvad O, Strunge B, Pedersen EB. Abnormally increased endothelin-1 in plasma during the night in obstructive sleep apnea: relation to blood pressure and severity of disease. Am J Hypertens. (2007) 20:44-52. doi: 10.1016/j.amjhyper.2006. 05.021

66. Ip MS, Lam B, Chan LY, Zheng L, Tsang KW, Fung PC, et al. Circulating nitric oxide is suppressed in obstructive sleep apnea and is reversed by nasal continuous positive airway pressure. Am J Respir Crit Care Med. (2000) 162:2166-71. doi: 10.1164/ajrccm.162.6.20 02126
67. Reale M, Velluto L, Di Nicola M, D’Angelo C, Costantini E, Marchioni M, et al. Cholinergic markers and cytokines in OSA patients. Int J Mol Sci. (2020) 21:3264. doi: 10.3390/ijms21093264

Conflict of Interest: The authors declare that the research was conducted in the absence of any commercial or financial relationships that could be construed as a potential conflict of interest.

Publisher's Note: All claims expressed in this article are solely those of the authors and do not necessarily represent those of their affiliated organizations, or those of the publisher, the editors and the reviewers. Any product that may be evaluated in this article, or claim that may be made by its manufacturer, is not guaranteed or endorsed by the publisher.

Copyright (๑) 2021 Zhang, Zhang, Fu, Wang, Yang, Wang, Zhou, Wang, Zhang and Xin. This is an open-access article distributed under the terms of the Creative Commons Attribution License (CC BY). The use, distribution or reproduction in other forums is permitted, provided the original author(s) and the copyright owner(s) are credited and that the original publication in this journal is cited, in accordance with accepted academic practice. No use, distribution or reproduction is permitted which does not comply with these terms. 